\title{
Prostituição e sentido de vida: relações de significado
}

\author{
Willian HeniqueCoṇ̂̂ - UnivesidadeFedłal doParaná, Cunitiba, Paraná, Brasil \\ AdrianoFurtadbHdanda- UnivesidadeFedarl doParaná, Curitiba, Paraná, Brasil
}

\begin{abstract}
$\overline{\overline{R e s u m o}}$
O presente artigo tem como objetivo elaborar uma compreensão fenomenológica acerca da prática da prostituição, relacionando essa experiência à busca pelo sentido da vida. Com base nos conceitos empregados pela Logoterapia - a psicoterapia do sentido de vida -, elaborou-se uma reflexão teórica sobre as possíveis motivações e sentidos que têm as mulheres que se dedicam à prostituição. Dentre essas, as principais seriam, o meio de sobrevivência econômica, insatisfação com a família, busca por status social, entre outras. Esses pontos foram articulados com a concepção de homem para Viktor Emil Frankl, enquanto aquele ser que está em uma insaciável busca pelo sentido de vida. Esperou-se, com isso, lançar luzes sobre essa relação.
\end{abstract}

Palarasdhave Sentido de vida; Prostituição; Fenomenologia; Logoterapia.

\begin{abstract}
Prostitution and sense of life: relationship of significance

This article aims to develop a phenomenological understanding about the practice of prostitution relating this experience to search for the meaning of life. Based on the concepts employed by Logotherapy - the psychotherapy of the meaning of life - is intended to make a theoretical reflection on the possible motivations and meanings that have women who engage in prostitution. Among those, we considered the means of economic survival, dissatisfaction with family, search for social status, among others. These points were linking with the conception of Man related to Viktor Emil Frankl, as the being who is in an insatiable search for the meaning of life. This was expected to shed some light on this relationship. Keguards Meaning of life, Prostitution, Phenomenology, Logotherapy.
\end{abstract}

\section{Prostitución y sentido de la vida: relaciones de significado}

\begin{abstract}
Resumen
La presente investigación tiene como objetivo elaborar una comprensión fenomenológica sobre la práctica de la prostitución relacionando esta experiencia a la búsqueda por el sentido de la vida. A partir de los conceptos empleados por la Logoterapia - la psicoterapia del sentido de la vida - se elaboró una reflexión teórica sobre las posibles motivaciones y sentidos que tienen las mujeres que se dedican a la prostitución. Entre ellas, las principales serian, el medio de sobrevivencia económica, insatisfacción con la familia, búsqueda por estatus social, entre otras. Esos puntos fueron articulados con la concepción de hombre para Viktor Emil Frankl, mientras un ser que está en una insaciable búsqueda por el sentido de la vida. Se esperó, con eso, lanzar luces sobre esa relación.

Palabras dave Sentido de la vida; Prostitución; Fenomenología; Logoterapia.
\end{abstract}

A Logoterapia, criada por Viktor Frankl (19051997), afirma que a busca pelo sentido da vida é a principal força motivadora do ser humano. Para Frankl, a vida é um dado concreto, de modo que as exigências que a vida nos faz sempre são bem concretas. Essa concreticidade está dada pelo destino do ser humano, que para cada um sempre é algo único e singular, já que nenhum ser humano e nenhum destino podem ser comparados com o outro; nenhuma situação se repete, diz Frankl (1985).

De acordo com a logoterapia, podemos descobrir o sentido da vida de três formas diferentes: a) criando ou praticando um ato; b) experimentando algo ou encontrando alguém e; c) pela atitude que tomamos em relação ao sofrimento inevitável. Por meio dessa revisão de literatura, tentaremos mostrar como a prática da prostituição é cerceada nessas formas de encontrar o sentido da vida. Sendo assim, partimos da hipótese que a prostituição, para muitas mulheres, além de ser um meio de sobrevivência, é também um meio de se buscar um sentido para a vida.

As mulheres que oferecem satisfação sexual em troca de remuneração vão perdendo seu corpo - por agressões e doenças - e 0 próprio destino, pois mergulham num mundo de ilusões e passam a desconstruir suas relações de proteção e de direito individual e coletivo, fazendo com que emerjam daí diversos fatores de risco (Bruns \& Guimarães, 2010).

Atualmente, os estudos sobre a prostituição feminina relacionam-se com temas variados, tais como a problemática das doenças sexualmente transmissíveis (Corrêa, Lonardoni \& Matumoto, 2008), os estudos de gênero e sexualidade (Barreto, 2008), o abuso de drogas (Andrade \& Nunes, 2009), a prostituição infanto-juvenil (Botelho, 2003; Molina, 2003; Molina \& Kodato, 2005) e a violência contra as mulheres que se prostituem (Diniz, 2009). Procuraremos relacionar a busca do sentido da vida com a prática da prostituição. Utilizaremos 0 referencial da logoterapia naquilo que ela pode nos ajudar a compreender essas relações e, possivelmente, lançar luzes para o fenômeno da prostituição.

\section{A nogãodehomempara a logterapia}

Na elaboração de sua teoria, Frankl sofreu influência dos pensamentos de Freud e Adler, de quem 
discorda em suas concepções de ser humano, rompendo com ambos e passando a defender suas próprias ideias. Para Frankl, o ser humano não pode ser concebido como um ser governado por pulsões, por ser esta uma visão determinista que não considera sua característica de ser livre e sua habilidade para fazer escolhas conscientes, assumindo, dessa forma, a responsabilidade pela sua vida. A liberdade, para Frankl, é o que confere humanidade ao homem, ou seja, a expressão do humano no homem (Xausa, 1986).

Contrariamente a teorias que afirmam a luta pela solução de tensões ou pela manutenção da homeostase (X ausa, 1986), a premissa da qual parte Frankl é de que o ser humano necessita de tensão, busca tensões e, inclusive, cria novas tensões (Frankl, 1978). "O homem de hoje, [...] já não é sexualmente frustrado, mas existencialmente frustrado. E hoje sofre menos [...] de um sentimento de inferioridade do que de um sentimento de falta de sentido, precedido por um sentimento de vazio, de um vazio existencial para sua vida" (Frankl, 1991, p. 155. Grifos nossos).

Frankl entende 0 homem como um ser tridimensional, sendo a primeira dimensão a samática (dos fenômenos corporais e da fisiologia); a segunda, a psicdógica (dos instintos, condicionamentos e cognições); e a terceira, a noúica (do grego nous que significa espírito), a qual abrange todas as qualidades que diferenciam 0 homem dos demais animais. 0 ponto de partida de Frankl é que o homem é essência espiritual (Frankl, 1985). Assim, a psicologia profunda reduziu todos os fenômenos à facticidade psicofísica, descuidando da pessoa, que é o centro da existência espiritual.

Concebendo o ser humano nessa totalidade, Frankl (1985) ressalta o espiritual como uma característica especificamente humana, sendo considerada uma das dimensões do ser que vai além do religioso ou supranatural, também se referindo a inclinações e afetos que não derivam só do instinto, mas que dizem respeito ao "espírito" humano no sentido filosófico, abrangendo, por exemplo, as produções artísticas, o sentido estético, etc. 0 espiritual ou noético é essencialmente distinto do psicológico, e não pode ser incluído na facticidade psicofísica, podendo ser tanto consciente quanto inconsciente. Para aprofundar este assunto, Frankl escreveu um livro intitulado A prenca ignarada de Deus explorando a questão e nomeando a espiritualidade inconsciente como "inconsciente transcendental".

A logoterapia, portanto, como uma "análise existencial" (Frankl, 1985), amplia o conceito de inconsciente, encontrando ali, além de uma impulsividade inconsciente, uma espiritualidade inconsciente. Assim, introduz na prática uma psicoterapia a partir do espiritual, entendida amplamente e incluindo a dimensão da religiosidade (Frankl, 1948/ 2007).

Ao reconhecer o inconsciente espiritual, afasta-se toda intelectualização e racionalização unilaterais sobre a essência do homem [...]. A espiritualidade inconsciente aparece como uma religiosidade inconsciente, ou seja, um estado inconsciente de relação com Deus, ainda por muitas vezes latente (Xausa, 1986, p. 194).

Quando a logoterapia conclui que há algo espiritual no inconsciente, pode-se descobrir, nessa relação, algo transcendente no inconsciente. Isso não seria uma forma de divinizar o inconsciente, nem de propor que D eus viva no inconsciente. Trata-se, antes, de uma tendência - um movimento, uma direção inconsciente para Deus (X ausa, 1986). Frankl, portanto, não considera o homem como encerrado por influxos deterministas de natureza biopsicológica nem só aberto aos determinismos do meio ambiente, mas como um sujeito que cria o mundo. Sua novidade teórica está na realização do homem pela autotranscendência em busca de um sentido da vida.

\section{O sentido da vida para a Logoterapia}

"O sentido da vida é um problema caracteristicamente humano e uma indagação que todo homem faz a si mesmo. Para assumir um compromisso com a vida é preciso descobrir-lhe o sentido" (Xausa, 1986, p. 139). Frankl considera que cada pessoa tem uma vocação própria ou missão específica na vida; cada um tem uma tarefa concreta exigindo realização. Mas tal tarefa - o sentido - não é algo estático: 0 sentido muda de acordo com a pessoa e a situação, uma vez que a existência de cada homem apresenta um caráter único e as situações nas quais estamos envolvidos são irrepetíveis (Frankl, 1946/ 1986). O sentido da vida não é uma especulação abstrata, é uma realização concreta no mundo.

Sentidb pode ser entendido, aqui, como um modo específico de dar forma à situação; é um tipo de "engajamento", um confronto criativo com a situação de cada hora (Roehe, 2005). Nas palavras de Frankl (1985):

[...] a pessoa não deveria perguntar qual o sentido da sua vida, mas antes deve reconhecer que é ela que está sendo indagada. Em suma, cada pessoa é questionada pela vida; e ela somente pode responder à vida respondendo por sua própria vida; à vida, ela somente pode responder sendo responsável. Assim, a Logoterapia vê na responsabilidade a essência propriamente dita da existência humana (p. 133). 
Para Frankl, somos nós que devemos "dar constantemente resposta à questão da vida, às questões vitais" (Frankl, 1990, p. 69). Frankl (1985) afirma que nenhum médico poderia responder à questão do sentido da vida em termos genéricos, pois este difere de pessoa para pessoa, de um dia para o outro. Sendo assim, o que importa não é o sentido da vida de um modo geral, mas o sentido de vida de uma pessoa em um dado momento.

Seria o mesmo que perguntar a um grande mestre enxadrista a respeito da melhor jogada em xadrez. Simplesmente não existe algo como o melhor lance ou um bom lance à parte de uma situação específica num jogo e da personalidade peculiar do adversário. 0 mesmo é válido para a existência humana. Não se deveria procurar um sentido abstrato da vida. Cada qual tem sua própria vocação ou missão específica na vida [...]. Nisto a pessoa não pode ser substituída, nem pode sua vida ser repetida (Frankl, 1985, p. 133).

Frankl também se ocupa em afastar a ideia de que o "sentido de vida" faça referência a um sentido total e globalizante. Analisar o sentido da vida genericamente coloca a questão em termos inapropriados; assim, a "vida" deve ser tomada como a existência concreta e singular de alguém, num dado contexto (Pereira, 2008). Cada situação de vida é única e nesse caráter Frankl delineia aquilo que quer fazer entender por "sentido".

0 sentido diz respeito à totalidade da vida de uma pessoa e também ao momento presente. Existe ainda um sentido último, mais amplo, o sentido da totalidade da vida de todos. Frankl (1948/2007) usa a seguinte metáfora: um filme é feito com milhares de fotos, mas o sentido do filme todo só será compreensível ao final da exibição. Assim, só é possível compreender 0 sentido da vida de uma pessoa como um todo no encerramento dessa vida.

Para a logoterapia, a realização do sentido satisfaz a aspiração mais básica do humano, que passa a compreender a própria existência como justificada, como força vital perene e incessante, mediante cuja afirmação radical se pode pensar a vida como uma espécie de missão pessoal e inalienável. Quando a pessoa encontra o sentido de sua vida, encontra aquilo que pode fazer e que exprime sua unicidade, a sua missão diante da vida. A realização pessoal vem como consequência de se atingir o sentido (Frankl, 1948/ 2007).

Além do sentido de situações únicas, existem os "universais de sentido", os valores. Frankl classifica-os em três categorias: os valores ciativos (pelos quais 0 homem dá algo ao mundo, por meio da ação concreta, como no trabalho, p. ex.); os valores viveniais (pelos quais o homem recebe algo do mundo, frui do que há de belo, como um pôrdosol, um filme, ou quando se entrega à pessoa amada); e os valores de atitude (como quando a pessoa se posiciona de forma digna diante do sofrimento inevitável) (Silveira \& Mahfoud, 2006). Nos valores de criação podem ser incluídas todas as criações intelectuais, artísticas, de trabalho e a realização profissional, que manifestam necessidades humanas fundamentais (X ausa, 1986). Se não há uma adequada visão ou realização desses valores, o homem se frustra, desviando o sentido da vida. Sendo assim, o ócio, a desvalorização, a desumanização do trabalho, as diversas formas de alienação e a frustração das potencialidades criativas podem levar 0 homem à despersonalização, a produzir o taedium vitae ou a revolta.

Os valores de experiência aparecem na gratuidade dos atos de receber; são as riquezas incomensuráveis da natureza que captamos na contemplação e todas as riquezas da cultura. E os valores de atitude são aqueles que surgem quando fatos irreparáveis e irreversíveis acontecem acima da capacidade humana de superá-los. Frankl fala na realização dos valores de atitude diante da tríade trágica da dor, da culpa e da morte; considerando um "privilégio específico do ser humano saber sofrer, assumir a culpa e considerar a transitoriedade e a finitude da vida" (Xausa, 1986, p.163). Todos esses temas, Frankl (1946/ 1986) desenvolve em seu texto Psicterapia e sentido da vida, levando a sua questão central - a do sentido da vida - e o quanto uma resposta a essa questão mobiliza as forças vitais do indivíduo. Em contrapartida a problemática do sentido, isto é, a ausência de sentido na vida, ou o vazio existencial é capaz de causar enfermidade (Frankl, 1948/ 2007).

\section{Prostituiçãoesentidbdevida: reaçâes designificadb}

Ao longo do tempo, o fenômeno da prostituição recebeu várias explicações acerca dos motivos que mobilizam a mulher a tal prática, relacionados ao trabalho, ao prazer e à patologia. Procuraremos ver 0 quanto essa prática pode ser encarada como uma forma de se encontrar um sentido na vida.

\section{Prostituição e trabalho}

Segundo Souza (2007), cada mulher apresenta motivos específicos para justificar sua prática, como estar desempregada, almejar sair da casa dos pais, necessitar de manter terceiros, como filhos e pais, e até mesmo buscar por um status social. Para Molina e Kodato (2005), a crise econômica e social pelas quais passa a maioria das mulheres é uma das principais causas de entrada na prostituição, e nesse espaço encontram uma possibilidade real de geração de renda suficiente e rápida. Essa escolha teria como fortes influências a necessidade de sustentar a família, em 
virtude da autorresponsabilização pela manutenção do grupo doméstico (o próprio, o dos filhos e de outros membros da família), e o baixo nível de escolarização, que dificulta sua inserção no mercado de trabalho. Na mesma direção, Gaspar (1985) afirma que a miséria econômica é vista, no Brasil, como um dos principais motivos de ingresso no mundo da prostituição e que as desigualdades econômicas e sociais fomentam a exploração e o comércio do sexo. Para continuar no mercado, as mulheres precisam se diferenciar em seus atributos físicos e sociais. Sendo assim, o culto à beleza e a preocupação com os modismos fazem parte do cotidiano dessas mulheres. Portanto, numa sociedade em que "ser bonita" e "estar bem vestida" é quase um sinônimo de realização pessoal, sucesso e felicidade, fugir a estes padrões pode ser visto como uma ameaça às possibilidades de trabalho (Gaspar, 1985).

Lipovetsky (2004) coloca que vivemos a época da hipermodernidade; um momento em que os valores morais, religiosos e políticos caíram em desuso, fazendo com que a sociedade atual seja marcada pelo excesso e pela velocidade. Portanto, 0 fator "sobrevivência" tem uma relevância importante nessa sociedade hipermoderna, pois 0 ambiente passou a ser dominado pelo tempo de risco, pela incerteza e pela insegurança (Bruns \& Guimarães, 2010). Para Lipovetsky (2004), nessa hipermodernidade está ocorrendo uma redução da valoração do presente para que se possa preocupar apenas com o futuro, que cada vez mais se apresenta como incerto e angustiante.

Corroborando essa questão, Andrade e Nunes (2009) realizaram uma pesquisa em Santo André, São Paulo, com adolescentes que se prostituíam e afirmaram que o principal motivo que fez que essas adolescentes saíssem às ruas foi a violência doméstica, agravada pela precária situação econômica de suas famílias, caracterizando uma exclusão socioeconômica. Como assinala Diniz (2009, p. 90):

Para grande parte das prostitutas, a prostituição ainda é considerada como algo transitório, apenas para garantir sua subsistência. [...] para aquelas oriundas de camadas sociais mais baixas, a perspectiva de mudança de atividade torna-se mais difícil em virtude do contexto da crise do capital, da reestruturação produtiva e do desemprego estrutural. Desse modo, a profissão deixa de ser uma opção individual, para se estabelecer enquanto alternativa na busca da sobrevivência.

Portanto, a prostituição é vista como uma estratégia de sobrevivência que muitas mulheres encontram para satisfazer suas necessidades mais básicas, como moradia e alimentação. Para outras, é 0 que se tem quando não há a abertura que esperavam do mercado de trabalho. A desesperança em encontrar uma ocupação diante do desemprego estrutural, acrescentando-se a falta de escolaridade e a baixa qualificação profissional, faz com que muitas mulheres acreditem que a prostituição é o caminho que lhes resta, pois não se faz necessário cumprir as exigências do mercado formal (Diniz, 2009). Para Frankl (1946/ 1986), a crise econômica, por si só, não força ninguém a adotar um comportamento determinado; pelo contrário, afirma: "0 que nos espanta é que frequentemente a mulher comum resista à tentação de recorrer à prostituição, a despeito das enormes dificuldades econômicas que atravessa" (Frankl, 1946/ 1986, p. 198).

Por outro lado, a prostituição pode ser uma maneira de ganhar muito dinheiro com rapidez, mais do que se ganharia em qualquer outra profissão, fazendo com que a mulher possa participar mais ativamente da sociedade de consumo (Bruns \& Guimarães, 2010). Nesse caso, a questão financeira não seria fator relevante apenas para as prostitutas de classe social baixa, pois existem profissionais do sexo da classe média e alta que buscam melhores condições financeiras, e pela prostituição poderiam se dar ao luxo de possuir uma vida mais confortável, que não apenas permitisse consumir-lhes, roupas de grife e perfumes caros, mas também ter sonhos e desejos de estar inseridas num mundo mágico, criado pela mídia e apresentado como lugar onde se é feliz (Bruns \& Guimarães, 2010). Este mundo mágico é um mundo criado, pois estamos diante de um mercado voltado ao consumidor, como afirma Bauman (1998), vigorosamente, com a intenção de manter uma procura infinitamente insatisfeita, ou seja, há sempre uma busca por novas experiências e sensações que irão aparecer, acreditando-se estar em busca da felicidade. Para Bauman (1998), a enorme sedução desse mercado acarreta uma grande divisão de águas: de um lado os que podem arcar com esses desejos e do outro aqueles que não podem, caracterizando, assim, uma marca de sucesso e fracasso.

Frankl aparece, então, com uma indagação: "Não é verdade que 0 homem, propriamente e originalmente, aspira a ser feliz?” (Frankl, 1990, p. 11). O homem realmente quer, em derradeira instância, não a felicidade em si mesma, mas antes um motivo para ser feliz. E é na prática da prostituição que a mulher busca esses motivos para ser feliz, acreditando ser a felicidade esse poder de consumir sem fronteiras. Mas, afirma Frankl, assim que o homem se sente motivado para ser feliz, a felicidade se fará presente; portanto, a felicidade não é um objetivo a ser almejado (Frankl, 1990); 0 caminho da realização de alguma atividade, profissional ou não, é a primeira forma de se encontrar um sentido na vida, portanto, não seria a prostituição uma maneira 
de se procurar o sentido da vida? Bruns e Guimarães (2010) afirmam que a prostituta é uma "atriz no mundo da realidade, que encena uma personagem para satisfazer seus clientes e, ao sair de cena, volta a ser a mulher que sempre foi" (p. 84), a mulher que passa necessidade com os filhos, que busca sua sobrevivência ou aquela mulher que busca um status social mais elevado, ou seja, há a procura por um motivo para ser feliz, portanto, a busca por um sentido na vida.

Nessa busca pelo sentido da vida, a mulher, prostituída, se depara com uma realidade em que a comercialização do seu corpo e o uso de drogas não podem ser mais dissociados, na medida em que as drogas promovem a entrega do corpo como mercadoria, isentando 0 sujeito, de um aprofundamento reflexivo quanto ao que se esta entregando ao pagador (Andrade \& Nunes, 2009). Exemplificando esse fato, temos pesquisas realizadas por Andrade e Nunes (2009) onde todas as adolescentes prostituídas que foram entrevistadas se referiram ao uso de múltiplas drogas diariamente. Corrêa e colaboradores (2008), entrevistaram 75 profissionais do sexo, da quais $94,7 \%$ consumiam bebidas alcoólicas e 67\% eram usuárias de algum tipo de droga, lícitas ou não, e o motivo alegado pela maioria delas estava relacionado à falta de perspectivas em relação à vida, à situação em que elas julgavam se encontrar ante a sociedade e a busca de audácia para exercer seu trabalho

Em outro estudo, Scheriner e colaboradores (2004) encontraram - numa amostra de 97 mulheres prostitutas - que $61 \%$ usavam bebidas alcoólicas. Mas 0 que chamou a atenção nessa pesquisa foi a prevalência de sintomas depressivos em 67\% das entrevistadas, sendo estatisticamente significativa a associação da presença desses sintomas com o uso de álcool, 0 histórico de doenças sexualmente transmissíveis e a ausência de prática religiosa. Segundo Botelho (2003), o uso de drogas na prostituição é visto como uma das formas das mulheres aguentarem a vida na rua, uma realidade que se apresenta como maneira de aprender a lidar com situações de falta de controle sobre suas vidas.

Por não estarem inseridas no mercado por meio de um trabalho formal, as mulheres que se prostituem buscam no álcool e nas drogas uma forma de aliviar seu sofrimento, suas preocupações, e muitas vezes entram em depressão. Frankl (1986) afirma que antes de se apresentar a depressão, o primeiro sintoma a se formar é a apatia, e eis que surge novamente a questão do sentido, visto que, ao experienciar a desocupação, esta é vivenciada como uma desocupação interior, um vazio de consciência. Para Frankl, esses sintomas são característicos de um profundo sentimento de que a vida não tem sentido, do vazio existencial, e conclui que vivemos numa época em que esse sentimento é predominante (Xausa, 1986). Assim, conforme os estudos verificados nos mostram, há na prostituição uma amostra significativa de mulheres que estão nesse vazio existencial, e que não conseguem encontrar um sentido para suas vidas, perdendo-se no vazio do sentido.

\section{Prostituição e Prazer}

Para Bruns e Guimarães (2010), a prostituição pode ser encarada como uma "forma de adolescentes realizarem sonhos criados pela sociedade do espetáculo" (p. 51). Assim, o ambiente da prostituição invariavelmente mistura-se com miséria, luxúria e ilusão de felicidade. Dessa forma, essas garotas almejam não somente dinheiro, mas poder e status

No entanto, o dinheiro que entra - com certa rapidez e com aparente facilidade - na prática da prostituição, vai embora com a mesma velocidade, pois é utilizado para satisfazer os mais variados caprichos das profissionais do sexo, realizando, assim, seus sonhos consumistas, algo que em outras profissões, a curto prazo, seria muito difícil de alcançar, e com a quantidade de dinheiro que se obtém, há a chance dessas mulheres se estabelecerem em um meio social economicamente mais elevado (Bruns \& Guimarães, 2010).

Mas "a prostituta, além da questão econômica, também realiza suas fantasias de ser desejada e amada pelo sexo masculino". Ou seja, além de buscar 0 pagamento, almejam o prazer sexual, que muitas vezes é obtido e por onde ocorrem momentos de afeto, amizade e companheirismo entre a prostituta e seu cliente. Na pesquisa realizada por Barreto (2008), as mulheres afirmavam que o sexo com os clientes é muito importante como fonte de prazer, suprindo coisas que não conseguem obter fora da prostituição. Isso mostra que, mesmo nessa condição, a pessoa que se prostitui busca afeto. Conforme o relato de uma prostituta: "cada um vem e [...], às vezes vem aqui pra estar conversando, falando, desabafando, e aí você aprende muita coisa" (Barreto, 2008, p. 48).

Nesse sentido, a prostituição pode, muitas vezes, ser uma atividade prazerosa. Barreto (2008) afirma que todas as entrevistadas disseram que sentem prazer com seus clientes, embora algumas digam que não é o que procuram. Portanto, na relação com o cliente, além de buscar 0 pagamento, também é almejado o prazer sexual, mostrando, assim, que há sentimentos e emoções envolvidas. Fonai e Delitti (2007) afirmam que a relação sexual pode ser um forte reforçador na prática da prostituição, além dos demais ganhos. Portanto, quando há essa expectativa por parte do 
cliente e da profissional do sexo, a relação pode ir muito além do aspecto comercial (Bruns \& Guimarães, 2010). Bruns e Guimarães (2010) afirmam que "[...] ao mesmo tempo em que alivia a necessidade sexual do homem, a prática está saciando algo dentro da dessa mulher" (p. 55).

A prostituição pode ainda ser vista como uma maneira de se vivenciar a sexualidade de forma livre. 0 desejo pela liberdade é tão forte quanto a necessidade de sustentar-se, exercendo, assim, o direito sobre sua própria sexualidade (Bruns \& Guimarães, 2010). Essa liberdade pode ser expressa não somente pelo número de parceiros, mas também por outras formas de expressar a sexualidade, como usar maquiagens e roupas ousadas, frequentar lugares proibidos e poder andar na rua como bem entenderem (Bruns \& Guimarães, 2010).

Frankl afirma que o homem é originalmente animado pela vontade para 0 sentido, para não dizer espiritualmente direcionado pela aspiração da plenitude possível de sentido em sua existência. Com igual intensidade luta por um conteúdo de vida significativo, e, somente onde tal vontade de sentido ficou irrealizada, tenta 0 homem anestesiar essa incompletude e inebriar-se de satisfação instintual (Frankl, 1990). Ou seja, a vontade de prazer se manifesta logo que se esvazia a vontade de sentido. Portanto, a prática da prostituição enquanto forma de busca pelo prazer também mostra esse vazio existencial e, por consequência, a incessante busca pelo sentido da vida. Para Frankl, 0 sentido da vida pode ser encontrado quando encontramos alguém (Frankl, 1990; Xausa, 1986), e na prática da prostituição a mulher buscaria esse alguém, que possa vir a preencher seu vazio e que possa enxergá-la e lhe dar um sentido para a vida. Conforme Botelho (2003, p. 116), muitas prostitutas "vislumbram a possibilidade de um salto, a chance de gerar uma família na sala em frente à televisão. Muitas nutrem a esperança de encontrar um príncipe encantado".

Frankl (1946/1986, p. 186) afirma que "um homem que 'possui' uma mulher, também a pode trocar; pode inclusive chegar a comprá-la”, como acontece na prática da prostituição. Para Frankl, dessa maneira, a mulher anda sempre cheia de cuidados com seu aspecto "externo", pois ela quer ser "tomada", ainda que não queira ser tomada a sério, ou seja, no que ela tem de verdadeiro e próprio, um ser humano dotado de um caráter, de algo único e irrepetível. D essa forma, se entregando aos desejos do homem, ela lhe dá aquilo que ele pretende "ter", e, assim, ficam ambos com as mãos vazias (Frankl, 1946/ 1986). D esse modo, a busca pelo prazer, na prostituição, se mostra como mais uma forma pela qual a mulher busca encontrar 0 sentido de sua vida.

\section{Prostituição e patologia}

A prostituição pode ser vista como uma forma de "patologia" quando se leva em consideração que "mulheres oriundas de famílias desorganizadas e carentes de afeto podem buscar nesta prática uma maneira de se sentirem amadas" (Bruns \& Guimarães, 2010, p. 68). Frankl (1991, p. 100) afirma que "o amor é a única maneira de captar outro ser humano no íntimo da sua personalidade". E muitas vezes, para as prostitutas, esse é um conceito que nunca encontraram em suas casas. Andrade e Nunes (2009) mostram em sua pesquisa, que a violência doméstica é um forte impeditivo ao retorno para casa, ainda que mantenham 0 desejo de voltar, o que é reforçado pela pesquisa realizada por Botelho (2003); como no seguinte relato: "Mil vezes eu estar aqui do que na minha casa, apesar de tudo que eu passo. Agora eu tenho dinheiro e não preciso mais deles" (Fonai \& Delitti, 2007, p. 107).

Molina e Kodato (2005) assinalam que um acontecimento comum nos grupos familiares é o fato de os filhos presenciarem as brigas dos seus pais e até agressões físicas do parceiro ou companheiro com relação à mãe. E muitas vezes também, ocorre a violência sexual por parte desses parceiros; assim, a fuga de casa torna-se uma estratégia, podendo ser esse um momento de travessia para a prostituição, conforme o seguinte relato: "certo dia eu cansei, eu não suportava mais, eu peguei e fui morar na rua, com 12, 13 anos" (Molina \& Kodato, 2005, p. 14). Da pesquisa de Botelho (2003) extraímos ainda o relato a seguir: "Meu pai e minha mãe me batiam desde os 3 anos de idade e só pararam com 13 anos quando eu saí de casa, e aí nada mais me segurou. Eles batiam na cara da gente, minha mãe me empurrou, era família que não tem amor igual as outras, que não tem carinho" (p. 96).

Dentro das próprias famílias existe um processo de exclusão diante da realidade que se apresenta, inclusive com rupturas nas relações de confiança, respeito e afeto. 0 sentimento que surge por não pertencer ao núcleo familiar faz surgir um grande anseio pela busca de uma identidade, que não consegue mais se ter em suas relações (Botelho, 2003). Em todas as entrevistadas, verificou-se que "sempre há alguém que de alguma forma as encaminha para a prostituição, confirmando 0 fato de que como não se sentem apoiadas e com um referencial sólido na instituição familiar, acabam por encontrar em outras pessoas aquilo que vem procurando" (Botelho, 2003, p. 92) e aquilo que tanto necessitam.

A fragilidade e a desestruturação das relações interpessoais, no seio familiar, se mostraram como solo 
fértil para que as situações de violência ali se instalassem e gerassem uma rede em cadeia de acontecimentos, favorecendo um baixo nível de autoestima, sentimentos de não-pertencimento e ausências de projetos de vida (Botelho, 2003).

Nessa mesma pesquisa realizada, foram verificadas, na história de vida das entrevistadas, situações de violência física, negligência e violência sexual doméstica incestuosa (Botelho, 2003), mostrando, dessa forma, que a prostituição, para muitas profissionais do sexo, é uma via onde se pode encontrar pessoas que lhes possam dar o carinho, atenção e amor desperdiçados em suas famílias. Diniz (2009) afirma que todas as entrevistadas de sua pesquisa descreveram histórias de violência que perpassam tanto a dimensão da prostituição quanto as dimensões afetivo-familiares.

Esse amor, que se inicia no seio familiar, para a logoterapia é um fenômeno tão primário como o sexo. Normalmente, sexo é uma modalidade de expressão do amor. Portanto, o sexo se justifica, e é até santificado, no momento em que for veículo do amor (Frankl, 1991). Sendo assim, muitas vezes esse envolvimento afetivo com os clientes, numa relação marcada por sexo, carinhos e afetos, é representado não somente pelo fator sobrevivência, mas por uma vontade de amar e ser amada; "0 amor precisa da realidade instintual, mas também o impulso instintual necessita do amor" (Frankl, 1990, p. 79).

Frankl (1990) afirma que a terceira forma de encontrar sentido para a vida é a decisão diante de um sofrimento inevitável. Muitas mulheres que se prostituem vêm de uma família desestruturada, marcada por violência de toda forma, e diante desse sofrimento buscam "dissipar suas angústias e ocupar este lugar vazio" (Bruns \& Guimarães, 2010, p. 67).

É possível que tenha havido uma desilusão relativamente à luta em torno do sentido da existência. A compensação por meio do anestésico sexual ocorre, em casos tais, com pessoas fracassadas em sua vontade de sentido. $\mathrm{Na}$ medida em que a exigência de um sentido da vida se esboça no vazio, a satisfação dos instintos é com tanto maior frequência e sofreguidão transformada em meio para um fim, ou seja, para o fim do prazer (Frankl, 1990, p. 80).

\section{Considerações finais}

O panorama histórico nos mostra que a prática da prostituição é um fenômeno atemporal, e que está ancorada ao binômio carência econômica vesus carência afetiva, próprio das relações sociais do sistema em que estamos inseridos (Bruns \& Guimarães, 2010). Esse sistema traz consigo alguns traços importantes, como o consumo em massa e a modificação de valores morais, religiosos e políticos de tempos em tempos.

Pudemos observar, em grande parte dos estudos citados neste trabalho, que a prostituição se apresenta como uma saída para a sobrevivência da mulher e de seus dependentes, ou uma forma de se obter melhores condições de vida, estimuladas pela mídia como um objetivo a ser alcançado para ser feliz. Nesse sentido, percebemos que há a preocupação pelo prazer, não somente com o prazer sexual, que algumas afirmam ter, mas o prazer por "consumir sem fronteiras". Mas serão esses prazeres capazes de tornar alguém feliz? Ou será uma maneira de anestesiar a dor que outrora vivenciou?

Não há como estudar a prostituição somente por uma via de pensamento. Há nessa prática uma série de fatores que acompanham o seu cotidiano, e que não exploramos neste trabalho, tais como o tráfico de drogas, as relações de gênero e tantos fatores que utilizam a prostituição para sobreviver. Portanto, mostra-se como um campo fértil de estudo da psicologia e outras áreas que podem tocar este tema e dialogar com outras visões.

Muito do que se percebe de relatos de mulheres em prostituição, como a afirmação por liberdade, por carinho ou mesmo por explorar a própria sexualidade, aponta para o que Frankl delimita como sendo a "vontade de sentido". São exemplos de caminhos alternativos que cada um de nós - naquilo que nos apresentamos ao mundo como seres únicos $\mathrm{e}$ irrepetíveis (Frankl, 1985) - buscamos para realizar aquilo que a falta de sentido ou o vazio existencial não nos permite.

Um dos caminhos apontados pela logoterapia é que, no enfrentamento das questões existenciais, buscam-se respostas e saídas para as angústias e o vazio existencial. Essa busca, muitas vezes, leva a situações como a prostituição - onde se vislumbram saídas alternativas. Todavia, como aponta Frankl (1948/ 2007), o humano é um ser que decide, portanto, responsável, e é essa responsabilidade que o faz ser "simesmo": "o ser humano [...] começa onde deixa de ser impelido, e cessa quando deixa de ser responsável" ( $\mathrm{p}$. 19).

A existência humana se dá nessa busca por sentido, sentido este que diz respeito à totalidade de sua vida e não somente ao seu presente. A logoterapia pode clarificar novos caminhos para alcançar o sentido da vida, mesmo que não se apresente como a solução para os dilemas da humanidade, mas como uma diretriz que mostra a necessidade de cada pessoa encontrar um sentido para a sua vida, para melhor atuar na sua realidade, em seu sofrimento, em sua existência. A 
logoterapia quer ajudar o ser humano a encontrar 0 "para que" viver, um sentido para a vida individual.

Nesse caminhar, as diversas respostas - como a prostituição - são perspectivas supostas, pois drogas e álcool "supostamente" aliviam 0 sofrimento, amortecem o vazio e se constituem, muitas vezes, nos mativos que dirigem a experiência subjetiva. Como afirma Frankl (1946/ 1986), a vida tem sentido a partir do momento em que a pessoa cumpre suas tarefas cotidianas e nelas encontra sentido. Assim, a falta de trabalho - a desocupação - que muitas vezes leva as mulheres à prostituição, ao álcool e às drogas, se torna o fardo da ausência do sentido.

O que a logoterapia pode representar - ou "dar pistas" (Silveira \& Mahfoud, 2006) - é a redescoberta da responsabilidade (como a afirmação de si na busca pelo sentido) e a consequente dissipação do vazio, na recolocação do sujeito como agente de sua própria vida. Nessa direção, é fundamental um olhar para a prostituição para além dos perfis da moral e do preconceito, num olhar que seja dirigida ao sæ por detrás do papel ocupado, como um ser que busca sentido.

Em um mundo marcado pelo egoísmo, hedonismo e consumismo, que despersonalizam e deformam o ser humano, a logoterapia é chamada a ser um caminho, uma via pela qual 0 homem pode amadurecer e aprender a conviver com seus limites e potencialidades, visando à compreensão na busca por sua principal força motivadora, a busca pelo sentido da vida. $\mathrm{E}$ ensinar que devemos dizer e viver um sim à vida, apesar de tudo o que acontece.

\section{Referências}

Andrade, A. G., \& Nunes, E. L. G. (2009). Adolescentes em situação de rua: prostituição, drogas e HIV/ AIDS em Santo André, Brasil. Psicoloja \& Sociedade, 21(1), 45-54.

Barreto, L. C. (2008). Prostituição, gênero e sexualidade hierarquias soiais e enfretamentos mo contexto de Bdo Hoizante(D issertação de Mestrado). Programa de Pós-Graduação em Psicologia, Universidade Federal de Minas Gerais, Belo Horizonte, Minas Gerais, Brasil.

Bauman, Z . (1998). O mal-estar da pósmodemidade Rio de Janeiro: Jorge Zahar.

Botelho, S. M. N. (2003). "Prostituição de addescentes": uma imagem contruída ma adtersidade da scieclade (Dissertação de Mestrado), Escola de Enfermagem de Ribeirão Preto, Universidade de São Paulo, Ribeirão Preto, São Paulo, Brasil.
Bruns, M. A. T., \& G uimarães, R. M. (2010). Garda de progama: uma nova enbalagem para o mesmo produto Campinas: Átomo.

Corrêa, N. A. B., Lonardoni, M. V. C., \& Matumoto, F. H. (2008). D oenças sexualmente transmissíveis em mulheres profissionais do sexo, Umuarama, Estado do Paraná, Revista Brasilèra de Análises Clínicas, 40(3), 209-213.

Diniz, M. I. (2009). Sileniosas esileniadas descritinandbas vidênias contra a mulher no catidiano da prosituição em Natal - RN (Dissertação de Mestrado). Programa de Pós-Graduação em Serviço Social, Universidade Federal do Rio Grande do Norte, Natal, Rio Grande do Norte, Brasil.

Fonai, A. C. V., \& Delitti, M. (2007). Algumas contingências mantenedoras do comportamento de prostituir-se. Reuista Brasileira de Terapia Compatametal eCogitiva, 9(1), 103-113.

Frankl, V. E. (1978). Fundamentos antropdóġos da psicterapia Rio de Janeiro: Zahar.

Frankl, V. E. (1985). Embusca desantida Petrópolis, RJ: Vozes.

Frankl, V. E. (1986). Psicterapia e sentidb da vida São Paulo: Quadrante. (O riginal publicado em 1946).

Frankl, V. E. (1990). A quesão do sentidb empicterapia Campinas: Papirus.

Frankl, V. E. (1991). Psicterapia para todos Petrópolis: Vozes.

Frankl, V. E. (2007). A presença ignarada de Deus Petrópolis: Vozes. (O riginal publicado em 1948).

Gaspar, M. D . (1985). Gardas deprogama: prostituiçãoem Copacabana eidatidadesoial. Rio de Janeiro: Zahar.

Lipovetsky, G. (2004). Os tempos hipemodemos São Paulo: Barcarolla.

Molina, A. M. R. (2003) Prostituição juvenil: uma condição existencial em busca de seus sentidos. Psicologa, Ciênaia eProfissãa, 23(2), 22-29.

Molina, A. M. R., \& Kodato, S. (2005) Trajetória de vida e representações sociais acerca da prostituição juvenil segundo suas participantes. Temas em Psicoloja, 13(1), 09-17.

Pereira, I. S. (2008). Mundo e sentido na obra de Viktor Frankl. Psico, 39(2), 155-159.

Roehe, M. V. (2005). Revendo idéias de Viktor Frankl no centenário de seu nascimento. Psia, 36(3), 311314. 
Sheriner, L., Junior, C. L. S., Paim, L. L., Baú, M. C., Ramos, F., Cardinal, T. M., Filho, E. V. C., Furtado, N. R., Martins, D. M., \& Picon, P. (2004). Prevalência de sintomas depressivos em uma amostra de prostitutas de Porto Alegre. Reista de Psiquiatria do Rio Grande do Sul, 26(1), 13-20.

Silveira, D. R., \& Mahfoud, M. (2006). Contribuições de Viktor Emil Frankl ao conceito de resiliência. EsudosdePsiclogia, 25(4), 567-576.

Souza, F. R. (2007). Saberes da vida na nate peceppões de milheres quepretam servicos sexuais sobre oedurar-senas rdaçães com seus diettes (Dissertação de Mestrado). Programa de Pós-Graduação em Educação,
Universidade Federal de São Carlos, São Carlos, São Paulo, Brasil.

Xausa, I. A. M. (1986). A picdoga do setido da vida Petrópolis, RJ: Vozes.

Sobre os autores:

Willian Henrique Comêa é graduado em Psicologia pela Universidade Federal do Paraná, participou nos eventos: V Congresso Brasileiro de Análise Existencial - Logoterapia; Seminário O Sentido dos Sonhos na Teoria de Viktor Emil Frankl e II Congresso Sul Brasileiro de Fenomenologia e II Congresso de Estudos Fenomenológicos do Paraná.

Adriano Furtado Holanda é psicólogo, mestre em Psicologia Clínica pela Universidade de Brasília, doutor em Psicologia pela PUC-Campinas e professor Adjunto do Departamento de Psicologia e da Pós-Graduação da Universidade Federal do Paraná.

Contato com os autores:

Departamento de Psicologia - Universidade Federal do Paraná.

Praça Santos Andrade, no 50, sala 215 (Ala Alfredo Buffren) - CEP 80060-240 - Curitiba-PR - Brasil.

E-mail: aholanda@yahoo.com 